\title{
Prolonged fever after pleural instillation of Corynebacterium parvum (Coparvax)
}

\author{
CLARE M LAROCHE, MARK BRITTON \\ From the Department of Thoracic Medicine, St Peter's Hospital, Chertsey, Surrey
}

Coparvax is a formalin killed freeze dried preparation of Corynebacterium parvum, used to prevent reaccumulation of malignant effusions when instilled into the pleural cavity. Side effects are usually reported as being mild and transient. We report three patients who experienced a more prolonged reaction than any previously reported.

\section{Case reports}

\section{CASE 1}

A 70 year old woman presented with a pleural effusion containing undifferentiated carcinoma cells. Biopsy of an enlarged cervical gland yielded material with the histological features of adenocarcinoma. She had a previous history of systemic lupus erythematosus and seropositive arthritis. Corynebacterium parvum ( $7 \mathrm{mg}$ in $20 \mathrm{ml}$ normal saline) was instilled into the pleural cavity after aspiration to dryness. On the evening of the procedure her temperature rose to $38.5^{\circ} \mathrm{C}$ and this was associated with nausea and tachycardia. The fever continued unabated for the next 10 days and was associated with a moderate rise in peripheral white blood count (maximum $16 \times 10^{9} / 1,83 \%$ neutrophils, on day six). Bacterial investigations, including sputum, blood, urine, and throat swab cultures, all gave negative results. The fever eventually settled on day 10 but she continued to experience night sweats for some time afterwards. So far, several months after the instillation, no further accumulation of her effusion has occurred. Despite the appearance of secondary deposits in her liver, the primary site of this woman's primary tumour remains elusive.

\section{CASE 2}

A 54 year old man presented with a right sided pleural effusion. Pleuroscopy showed disseminated pleural metastases and histological examination showed squamous cell carcinoma. No primary endobronchial lesion was seen on bronchoscopy. Corynebacterium parvum $(7 \mathrm{mg}$ of Coparvax in $20 \mathrm{ml}$ of normal saline) was instilled into the pleural cavity after aspiration of $3200 \mathrm{ml}$ of pleural fluid over the previous two days. That evening his temperature rose to $40^{\circ} \mathrm{C}$ and over the next 24 days he continued to have a swinging pyrexia (fig 1) associated with a raised erythrocyte sedimentation rate $(\mathrm{ESR}$ - maximum $105 \mathrm{~mm}$ in one hour on day five) and a maximum peripheral white blood cell count of $12.3 \times 10^{9} / 1$. A chest radiograph taken on the day after Corynebacterium parvum had been given showed no evi-

Address for reprint requests: Dr Mark Britton, St Peter's Hospital, Chertsey, Surrey KT160PZ.

Accepted 15 December 1986 dence of lobar or segmental collapse. On day six a chest radiograph suggested reaccumulation of the effusion and repeat aspiration from several sites yielded a further $350 \mathrm{ml}$ of pleural fluid. All bacteriological cultures (including the culture of pleural aspirate) were negative. He was treated symptomatically with aspirin and his temperature eventually settled spontaneously.

\section{CASE 3}

A 67 year old man received a pleural instillation of Corynebacterium parvum ( $7 \mathrm{mg}$ of Coparvax in $20 \mathrm{ml}$ of normal saline) for a malignant effusion secondary to adenocarcinoma, after aspiration of about $6000 \mathrm{ml}$ of fluid over the preceding few days. On the evening of the procedure his temperature rose to $38^{\circ} \mathrm{C}$ and remained raised for the next seven days. Again cultures (sputum, blood, urine, and throat swab) were negative. The fever was associated with a raised peripheral white blood cell count (maximum $14.9 \times 10^{9} / 1$, $88 \%$ neutrophils, on day six) and a raised ESR (increasing from a pretreatment value of 13 to $100 \mathrm{~mm}$ in one hour by day four). On day four he started a course of radiotherapy for his primary tumour. On day seven, because of considerable malaise, prednisolone ( $20 \mathrm{mg}$ daily) was started in an attempt to suppress the reaction presumably occurring in his pleural cavity; but there was no response after four days (fig 2). His ESR remained high (111 mm in one hour) and his white blood cell count was $10.6 \times 10^{9} / 1$. The chest radiograph showed reaccumulation of fluid with loculation, but aspiration at several sites removed only $150 \mathrm{ml}$ of sterile fluid. On day 12 treatment with amoxycillin, $500 \mathrm{mg}$ three times daily, was started with no sustained improvement. His

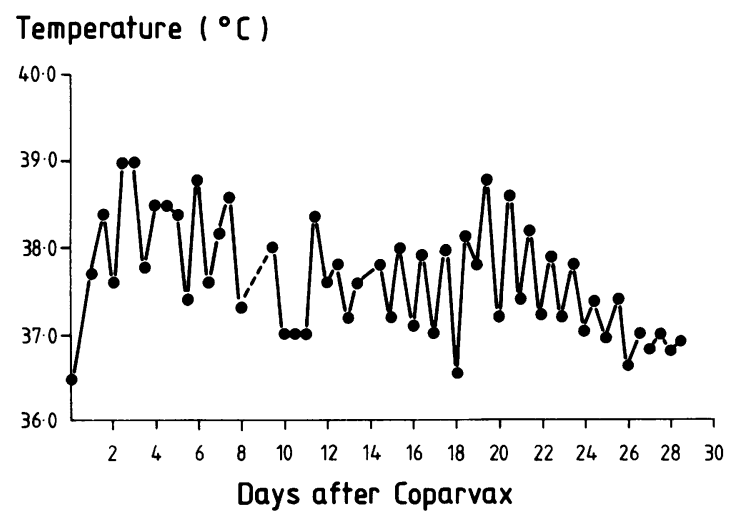

Fig 1 Patient 2: Temperature chart: morning and evening values. 


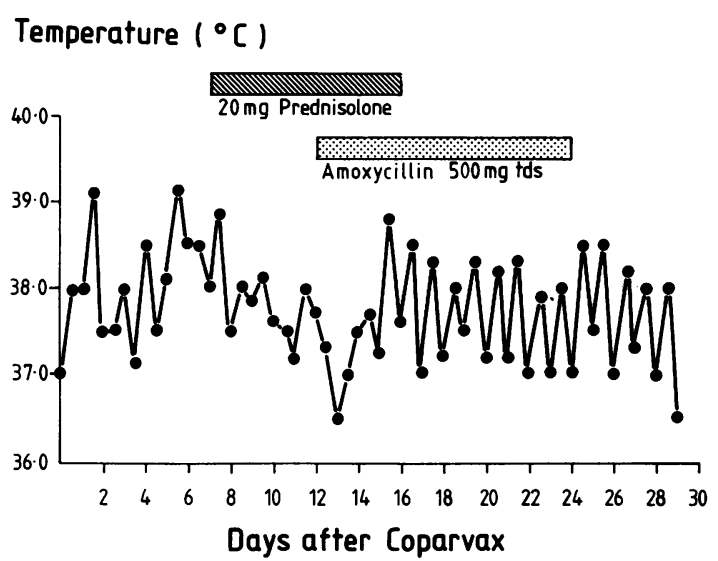

Fig 2 Patient 3: Temperature chart: morning and evening values.

temperature eventually settled after 40 days following treatment with co-trimoxazole and prednisolone $(20 \mathrm{mg}$ daily).

\section{Discussion}

Corvnebacterium parvum incites a vigorous reaction in serous membranes, probably acting as a sclerosant. ${ }^{12}$ After treatment aspirates contain macrophages and neutrophils, ${ }^{13}$ but the immune stimulant effect found with parenteral use is not thought to be important. ${ }^{4}$ No cause was found for the prolonged fever in any of our patients. Infection was not completely excluded in the first patient as she did not have a repeat pleural aspiration, but it seems unlikely in view of the eventual resolution of her fever without antibiotics. An abnormality of suppressor $\mathrm{T}$ cell function, a known feature of systemic lupus erythematosus, may have been a contributing factor in this patient. No immunological $\stackrel{?}{\rightarrow}$ abnormalities were apparent in the other two patients. We made no attempt to improve the apposition of pleural sur- 흠 faces with negative pressure drainage after insertion of Corynebacterium parvum. This led to a prolonged period of con- $\overparen{\nabla}$ tact between Corynebacterium parvim and the pleural surfaces, possibly increasing the chance of a severe reaction. The ampoules of Coparvax used were from different $\overrightarrow{0}$ batches, making contamination unlikely.

Mild fever is the side effect most commonly reported after $\vec{\omega}$ pleural instillation of Corynebacterium parvum, but it usu- $\rho$ ally lasts only two to three days at most. ${ }^{1-3}{ }^{-3}$ Our cases $\overrightarrow{\vec{x}}$ show that more severe reactions are not uncommon. The prolonged fever was associated with considerable malaise ? and necessitated prolonged hospital stays. Moreover a $\vec{\circ}$ fourth patient has had a similar reaction recently in this hospital (Dr J Stewart, personal communication). This potential $\omega$

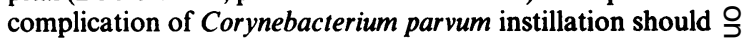
be carefully considered when an agent is being selected for chemical pleurodesis.

\section{References}

1 Webb HE, Oaten SW, Pike CP. Treatment of malignant ascitic and pleural effusions with Corynebacterium parvum. Br Med J 1978;1:338-40.

2 Millar JW, Hunter AM, Horne NW. Intrapleural immunotherapy with Corynebacterium parvum in recurrent malignant pleural effusions. Thorax 1979;35:856-8.

3 Felletti R, Ravazzoni C. Intrapleural Corynebacterium parvum for malignant pleural effusions. Thorax 1983;38:22-4.

4 Rossi GA, Felletti R, Balbi B, et al. Treatment with Coryne- $\frac{2}{(D)}$ bacterium parvum of recurrent malignant pleural effusions: a fibrogenic or an immunomediated process? [abstract]. Bull $\overline{\bar{\sigma}}$ Europ Physiopathol Respir 1986;22(supp 8):132.

5 McLeod DT, Calverley PMA, Millar JW, Horne NW. Further experience of Corynebacterium parvum in malignant pleural effusion. Thorax 1985;40:515-8. 